\title{
Papers
}

\section{Organizational Integration Strategies for Promoting Enduring Donor Relations in Higher Education: The Value of Building Inner Circle Network Relationships}

Received (in revised form): March 28, 2007

\section{Tanise L. Chung-Hoon}

is the Director of Principal Gifts in the Office of the President for LDS Philanthropies, Brigham Young University. She is a Certified Fund Raising Executive (CFRE). Her research focuses on enduring donor relations, principal gift-level donor activity, donor inclination, and the role of organizational integration in creating long-term support for nonprofit institutions.

\section{Julie M. Hite}

is an Associate Professor of Organizational Leadership at Brigham Young University in the Department of Educational Leadership and Foundations. Her research focuses on strategic networks of educational organizations, particularly as they affect resources, innovation, and educational performance.

\section{Steven J. Hite}

is a Professor of Educational Research Theory and Methodology at Brigham Young University in the Department of Educational Leadership and Foundations. His current research and service endeavors include the application of geographical information systems with educational management information systems in the national and regional education sectors of Africa and South Asia.

\section{Abstract}

Successful fund-raising efforts are critical for public higher education institutions as they seek to offset uncertainty in government funding. This

Author's Contact Address:

Tanise L. Chung-Hoon

Brigham Young University

C-380 ASB

Provo, UT 84602, USA.

Tel: $+1801422-9033$

Fax: +1 801 422-0405

E-mail: tanise@byu.edu study evaluated the enhancement of fund-raising capacity through the maintenance of enduring donor relationships. Utilizing the Donor/ Organization Integration Model, the study examined interactions with top ten donors at 132 public higher education institutions in the United States. Findings indicate that the combination of relational embeddedness and formal structural interaction was related to enduring donor relationships 
and was also related to greater fundraising outcomes. The study identified inner circle donor behaviors and fundraising strategies contributing to enduring donor relationships.

International Journal of Educational Advancement (2007) 7, 2-19. doi:10.1057/palgrave.ijea.2150048

Keywords:

donor relationships, fund-raising outcomes, integration

\section{Introduction}

To effectively maintain institutional survival and growth, particularly with the increasing difficulty of obtaining sufficient financial support from state and federal government, higher education institutions are realizing they must develop additional revenue streams (Mora and Nugent, 1998; Bloland, 2002; Altbach, 2004). For higher education, private philanthropic giving has been a significant source of such outside revenue (Cutlip, 1990; Hall, 1992; Prince and File, 1994; Gonzales-Campoy, 1996; Havens and Schervish, 2001). Owing to the increasing demand for external funding, educational fund raising in the United States is, however, increasingly a competitive enterprise (Jackson and Glass, 2000; Council for Advancement of Education (CAE), 2003). Therefore, higher education institutions need to enhance their fundraising capacity to successfully compete for external donor funding. Doing so will require higher education institutions to carefully examine their current organizational integration strategies for sustaining these critical philanthropic partnerships with private donors (Dierickx and Cool, 1989;
Barney, 1991; Dyer and Singh, 1998; Whipple and Frankel, 2000; Altbach, 2004; Chung-Hoon et al., 2005).

With the increasing competition and variety of charitable investment opportunities, donors expect more from their philanthropic experiences (A.S.C. Grant, 2001; Havens and Schervish, 2001). Top donors seek fund-raising involvement beyond the traditional give and take relationship, allowing them a role of increasing influence or control (Dunlop, 1987). Thompson (1967) introduced the idea of an "inner circle" (p. 140) of individuals who influence organizational operations. Ideally, inner circle donor relationships facilitate enduring donor relationships manifested in sustainable financial commitments. Specific interactions with top donors may be related to organizational integration of donors and stronger enduring donor relationships that can positively influence fund-raising practice and outcomes such as donors giving time, talent, and resources to see the organization succeed (Schervish, 1997; Kelly, 1998; Chung-Hoon et al., 2005).

The Donor/Organization Integration Model (DOIM) (see Figure 1) (ChungHoon et al., 2005) identifies two critical constructs that classify interactions with donors and may explain the development of enduring donor relationships. The first construct, relational embeddedness interaction, is defined as the strength of an individual donor or potential donor's relational connection to people within the organization or the extent to which the interactions are embedded within social relationships (Hite, 2003; Uzzi, 1996). The second construct, formal structural interaction, denotes the degree to which an individual donor or potential donor 


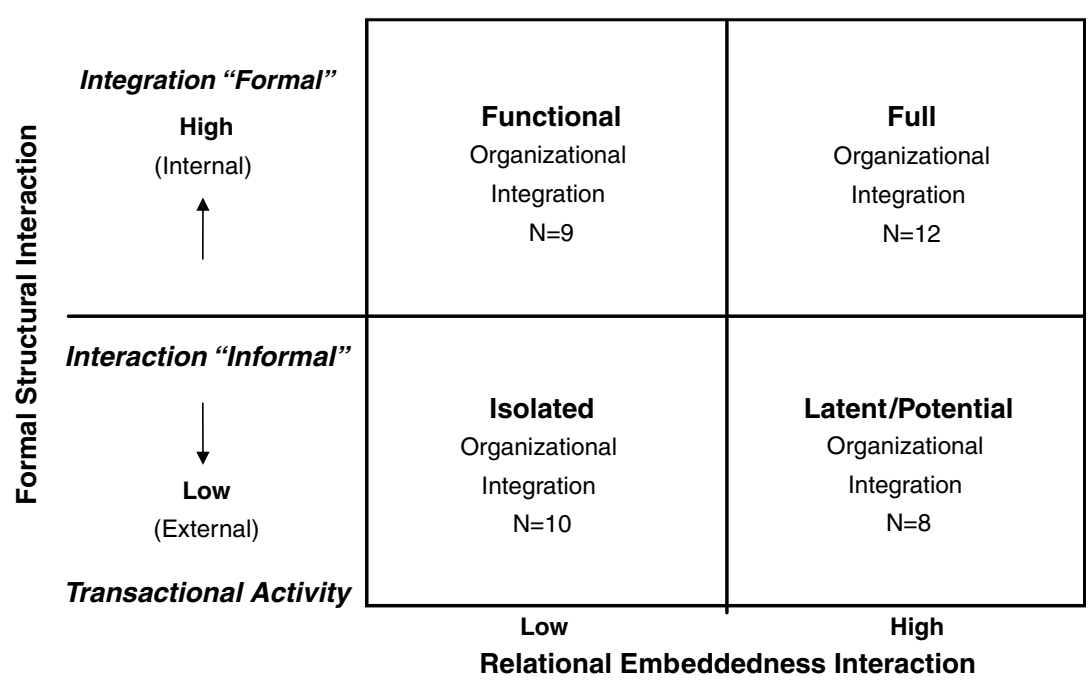

Figure 1: Donor/Organization Integration Model.

is integrated within the formal structure of the organization. The DOIM illustrates the confluence of these two constructs and creates a matrix to categorize the type and level of integration within organization/donor interactions (see Figure 1).

Each quadrant of the model identifies a level of structural and relational connection to the organization. For example, an event ticket purchase or a patron of the university bookstore would be placed in the isolated quadrant because this integration denotes low relational and structural linkage. A formally appointed individual, perhaps a state trustee, would have a high formal connection to the institution, but relationships may be superficial thus placement in the functional quadrant of the model. A former faculty member, alumnus, or community leader without current institutional roles or formality who maintains significant personal relationships with university staff would be characterized by the latent/potential quadrant. The ideal relationships, those donors who are significantly engaged with the institution both relationally and structurally, are illustrated within the full integration quadrant.

This study used the DOIM to classify organizations in terms of their interactions with top donors and examined whether donor integration strategies and outcomes differed by DOIM classification and whether a relationship existed between enduring donor relations (EDR) and fund-raising outcomes (FRO). Understanding the donor integration strategies associated with enduring donor relationships can help organizational leaders in higher education to formulate institutional fund-raising strategies and policies to improve FRO. To this end, the study focused on four research questions (see Figure 2 for research model):

1. To what extent does the DOIM (a) reflect a valid classification of top donor interactions? 


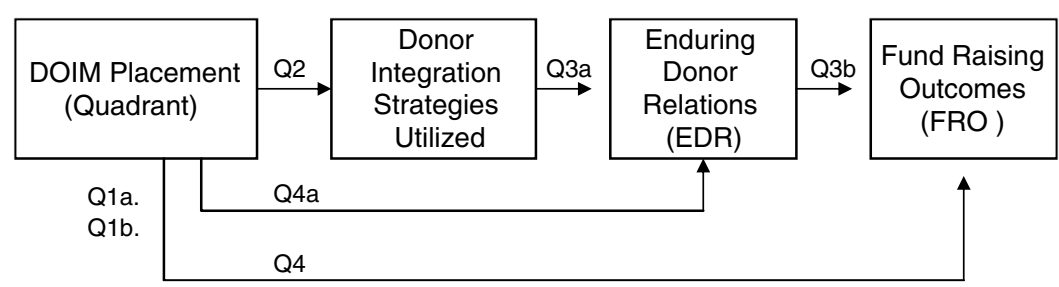

Figure 2: Research question visualization map.

(b) depend upon institutional characteristics for placement within the model?

2. Is institutional placement within the DOIM associated with the type of donor integration strategies utilized?

3. To what extent are

(a) integration strategies associated with EDR?

(b) EDR associated with FRO?

4. To what extent do

(a) EDR differ by DOIM quadrant?

(b) FRO differ by DOIM quadrant?

The results of this study indicated that the combination of relational embeddedness interaction and formal structural interaction increased the ability of an organization to use integration strategies that build inner circle relationships. These relationships are critical for developing those enduring donor relationships that promote fund-raising success.

While fund-raising research has primarily examined fund-raising efforts from a donor standpoint (e.g. Lord, 1983; Panas, 1984; Nicklin, 1995; Taylor and Shaw, 1997; R.M. Grant, 2001; Havens and Schervish, 2001; Schervish, 2001), few studies have examined fund raising from an organizational perspective (Tempel, 1991; Loessin and Duronio, 1993; Kelly, 1995; Young, 1997; Durham and Smith, 2001). This study assumes that competition for limited donor resources is driven by the philanthropic marketplace. Institutions organized and prepared to attract and retain donors will increase their ability to generate the needed resources to survive and grow (Duderstadt, 1997; Cash, 2002). Building a competitive advantage in fund raising is a critical strategy for higher education institutions as they vie to influence and control increasingly scarce external resources.

\section{Methods}

\section{Sampling}

This study tested the DOIM (ChungHoon et al., 2005) among a stratified sample of US public higher education institutions. The first sampling criterion was membership in the Council for Advancement and Support of Education (CASE). The second sampling criterion was Carnegie Classifications (Carnegie, 2000). Institutions classified in Research I, Masters II, and Baccalaureate/Associate institutions were selected because the number of institutions in each category provided an adequate survey 
sample size and because these classifications provided a clear typology to define organizational activities and processes. The third sampling criterion, organizational size, defined as student headcount enrollment average, ensured the inclusion of institutional fund-raising operations at small, medium, and large schools. This sampling strategy identified 132 institutions of higher education for inclusion in the study.

Using a purposeful selection strategy, respondents within each institution were selected from the 2003 CASE Membership Directory based on job titles likely to be relevant to major gift efforts or acting as university spokespersons. If an institution had fewer than 10 persons in the CASE directory, all were included regardless of title. If an institution had more than 10 persons listed, only 10 were included, with the first selection criterion being a position of spokesperson, the second criteria being a position of director or major gift officer, and the third being other positions traditionally relevant to fund raising. This respondent selection strategy identified 1,201 individuals within the 132 institutions. In addition, a snowball sampling strategy invited respondents to identify other potential respondents who were directly involved in the institution's fund-raising activities, resulting in an additional 15 respondents.

An invitation to participate in the survey was sent via e-mail to potential respondents using SurveyMonkey.com (Surveymonkey.com, 2004), an online survey creation and management tool (Schaefer and Dillman, 1998). Respondents chose to participate by accessing the survey link in the invitation email. They were sent one reminder or thank you e-mail. The thank you email triggered the snowball sampling strategy asking respondents to forward the survey to other institutional contacts relevant to fund raising.

An institutional response was defined as the institution meeting one of three criteria: (1) three or more total respondents, (2) one response by a university spokesperson or (3) a proportional response of 33 percent or more of the institution's eligible respondents. Of the 132 identified institutions, 66 (50 percent) had a valid institutional response. The operationalization of the institutional response averaged the data from all respondents from that institution to create organizational-level measures.

Fourteen (11 percent) institutions responded but did not qualify as an institutional response while 52 (39 percent) had no individual-level response. Nonresponse bias was examined using four criteria-two institutional demographics and two selection criteria: (1) age of institution, (2) enrollment, (3) geographic location, and (4) Carnegie classification. Oneway analysis of variance (ANOVA) with S-N-K and Tukey's post hoc tests found no significant differences for age or enrollment. Using chi-square, no significant differences were found for geographic location or Carnegie classification.

As the DOIM had been previously explored using only qualitative case study methods (Chung-Hoon et al., 2005), a 44-question quantitative survey instrument, the National Survey of Fund Raising Practice (NSFRP), was developed to specifically 
assess individual and institutional demographics, respondents responsibilities and involvement in fund raising, and the model's five constructs of (1) relational embeddedness interaction, (2) formal structural interaction, (3) integration strategies, (4) EDR, and (5) fundraising success outcomes. For the model's constructs, respondents were asked to describe interactions with their "top ten donors," in terms of either their individual fund-raising assignment or from an overall institutional perspective, using a 10-point continuous scale. Because this was the first trial for the scale, a 10-point scale was selected to give greater variability to responses and ability to gauge extremes. Survey items represent theory-based constructs from organizational, network and fundraising theory (Chung-hoon, 2005). In addition to the NSFRP Survey, the Voluntary Support of Education report (Council for Advancement of Education (CAE), 2002) provided a secondary source of institutional fund-raising data for each institution, making available specifically reported FRO and enrollment levels for 59 of the 66 qualifying institutional respondents.

\section{Constructs and Variables}

Factor analysis tested the validity of survey constructs, assessing the extent to which survey items accurately represented each area of the model. As expected, five components aligned with the main elements of the DOIM. These underlying components were identified as relational embeddedness interaction, formal structural interaction, integration strategies, EDR, and FRO. Each component had eigenvector values over 1.00 , and when combined explained 78.97 percent of the data. Reliability analysis provided further evidence of scale validity for these components (see Table 1).

In further analysis, relational embeddedness interaction was represented as the average of the three variables that loaded on this component (explained variance $=21.33$ percent; $\alpha=0.88$ ). The component of FRO had the highest explained variance (30.324 percent); however, given only a somewhat compelling alpha score $(\alpha=0.69)$, FRO were examined individually to provide more detailed and robust explanations. EDR (explained variance $=11.327$ percent) had four variables that loaded on this component. Given the low alpha score $(\alpha=0.10)$ however, each variable was used individually. Similarly, integration strategies had six variables that loaded on this component but provided only an explained variance of 8.506 percent $(\alpha=0.14)$. Therefore, each variable was used individually. For formal structural interaction, given low reliability alpha scores, the single variable of number of top ten donors with formal position or role at the institution was chosen to represent this construct and, therefore, determine an institution's $Y$-axis placement in the model. Organizational and operational demographics, particularly those based on the selection criteria, reflected the context of the individual institution and enabled grouping of institutions. 
Table 1: Factors identified in quantitative analysis and variables associated with each factor

\begin{tabular}{|c|c|c|c|}
\hline Factor & Survey questions & \multicolumn{2}{|c|}{$\begin{array}{l}\% \text { Explained variance } \\
\text { and reliability (alpha) }\end{array}$} \\
\hline $\begin{array}{l}\text { Relational } \\
\text { embeddedness }\end{array}$ & $\begin{array}{l}\text { Fund raisers care about donors Q16A } \\
\text { Fund raisers will always tell donors the } \\
\text { truth Q16B } \\
\text { Fund raisers will not take advantage of a donors } \\
\text { generosity Q16C }\end{array}$ & 21.33 & $\alpha=0.8808$ \\
\hline Fund raising outcomes & $\begin{array}{l}\text { Total dollars raised } \\
\text { Unrestricted dollars raised } \\
\text { Number of Alumni Donors } \\
\text { Endowment level for the institution }\end{array}$ & 30.32 & $\alpha=0.6723$ \\
\hline $\begin{array}{l}\text { Enduring donor } \\
\text { relations }\end{array}$ & $\begin{array}{l}\text { How likely is it that a donor asks for and takes } \\
\text { suggestions regarding gift designation and direction } \\
\text { from fundraiser? Q19 } \\
\text { How many of the top } 100 \text { donors have given an } \\
\text { ultimate gift? Q } 28 \\
\text { How many of the top } 10 \text { donors have the institution } \\
\text { as their primary charitable focus? Q } 25 \\
\text { How many of the top } 10 \text { donors initiate contact } \\
\text { with the fundraiser? Q } 20\end{array}$ & 11.33 & $\begin{array}{l}\alpha=0.1028 \\
\text { Factors } \\
\text { Utilized } \\
\text { Singly }\end{array}$ \\
\hline Integration strategies & $\begin{array}{l}\text { What is the organization's structure? Q7 } \\
\text { The organization has an ongoing, well-communicated } \\
\text { strategy Q8 } \\
\text { How many interactions with donors are strategically } \\
\text { planned and managed? Q17 } \\
\text { For your top } 10 \text { donors, how many continue } \\
\text { to give annual gifts in addition to their current } \\
\text { or past major gifts? Q } 26 \\
\text { How many of the top } 10 \text { donors work with and } \\
\text { know other top } 10 \text { donors outside of their campus } \\
\text { involvement? Q } 24 \mathrm{~B} \\
\text { How many of the top } 100 \text { donors have a } \\
\text { close relationship with your top campus } \\
\text { official? Q } 30 \\
\text { How many of the top } 10 \text { donors have a } \\
\text { personal friend among employees? Q } 23\end{array}$ & 8.51 & $\begin{array}{l}\alpha=0.1373 \\
\text { Factors } \\
\text { utilized } \\
\text { singly }\end{array}$ \\
\hline $\begin{array}{l}\text { Formal structural } \\
\text { interactions }\end{array}$ & $\begin{array}{l}\text { How many of the top } 10 \text { donors have a } \\
\text { formal position or role? Q21 }\end{array}$ & 7.48 & $\begin{array}{l}\text { Single } \\
\text { Factor }\end{array}$ \\
\hline Unexplained factors & $\begin{array}{l}\text { Variance in the model from unexplained or } \\
\text { unidentified factors }\end{array}$ & 21.03 & \\
\hline
\end{tabular}




\section{Data Analysis and Hypotheses}

To address the first research question, data analysis identified and assessed each institution's interactions with top donors relative to the four quadrants in the DOIM focusing on the following two hypotheses:

\section{$\mathrm{H}_{1 \mathrm{a}}$ : Institutions will be evenly distributed across quadrants in the DOIM. \\ $\mathrm{H}_{1 \mathrm{~b}}$ : Institutional characteristics will differ by DOIM quadrant.}

Institutions were placed into a DOIM model quadrant based on their institutional responses to the questions in the NSFRP for relational embeddedness interaction and formal structural interaction. To do this, the institutional response for each component was recoded as low or high, using the mean score as the cut point (relational embeddedness interaction mean $=8.0$ on a 10.0 scale; formal structural interaction mean $=6.8$ on a 10.0 scale). The relatively high means likely resulted from responses reflecting institutional interactions with top 10 donors. If the institutions had responded for all donors, these means would likely be lower. Based on the institutional response for both the $X$-axis and $Y$-axis, institutions were categorized into one of the four quadrants (refer to Figure 1).

Using independent samples $t$-tests and Mann-Whitney tests, analysis examined differences in institutional characteristics by quadrants. Due to the small number of institutions in each quadrant, comparisons were made between quadrant opposites representing the extremes (low, low vs high, high) and the two interaction component extremes (high, low-mainly relational embeddedness interaction-vs low, high-mainly formal structural interaction).

The second research question explored the differences in strategies used based on quadrant membership. Using ANOVA, analysis focused on the following hypothesis:

\section{$\mathrm{H}_{2}$ : Use of donor integration strategies will differ by quadrant.}

The third research question first addressed the association of integration strategies and EDR and then addressed the association of EDR and FRO. A critical purpose of this research question was to examine whether these three variables were distinct components and whether they were related. Using Pearson and Spearman correlation, analysis focused on the following hypotheses:

\section{$\mathrm{H}_{3 \mathrm{a}}$ : Integration strategies will be associated with EDR. \\ $\mathrm{H}_{3 \mathrm{~b}}$ : EDR will be associated with FRO.}

The fourth research question addressed whether quadrant placement influenced differences in organizational outcomes, particularly in terms of the level of EDR and FRO. Using Independent Samples T-tests and Mann-Whitney tests, analysis focused on the following hypotheses:

\section{$\mathrm{H}_{4 \mathrm{a}}$ : Evidence of EDR will differ by quadrant. \\ $\mathrm{H}_{4 \mathrm{~b}}$ : FRO will differ by quadrant.}


Methodological Limitations

Given the organizational-level focus, the main limitation was the small population due to the limited number of institutions in the three Carnegie classifications and CASE geographic districts. As a result, the study was not able to describe or compare institutions by Carnegie classification and geographic location. The second limitation was the broad identification of respondents. A response sample identifying only major gift officers, principal gift officers, and fund-raising administrators might have provided better data more specifically related to top donor/organization interactions. The third limitation was the use of a new survey instrument with previously untested constructs. As a result, cautious consideration was given to the validity and reliability of the survey questions, which somewhat limited flexibility of data analysis. Future research should address these limitations in survey population, respondents, and instrument development.

\section{Findings}

\section{DOIM Classification of Institutions}

Hypothesis $1 \mathrm{a}$ addressed whether the DOIM reflects a valid classification of interactions of top donors with public higher education institutions. This classification of institutions was based on the combination of their institutional responses to relational embeddedness of interaction and formal structural interaction. Findings indicated that 39 institutions (59 percent) had sufficient data to be classified into a specific quadrant in the model. The distribution of these 39 institutions is nearly equal in each quadrant, with 10 transactional, nine functional, eight latent/potential, and 12 full integration institutions. This distribution suggests that the DOIM model represents a valid classification system for the interactions of the higher education institutions with their top 10 donors, as each quadrant is well represented. Representation within each quadrant verifies that there is a distinct difference between quadrants and that each cell of the model is needed to illustrate the spectrum of unique donor interactions. This finding confirmed Hypothesis 1a.

Hypothesis $1 \mathbf{b}$ addressed whether quadrant membership reflected differences in organizational characteristics. No differences were found between the quadrants for institutional age, enrollment levels based on headcount, or Carnegie classification. Quadrant membership, however, did indicate a difference in geographic location between the functional integration and latent/ potential integration quadrants. Institutions in the functional integration quadrant were more likely to be located in the western part of the United States than those in the latent/ potential integration quadrant $(p<0.05)$. These findings may reflect the historical pattern of the earlier establishment of higher education institutions in the eastern and southern United States than in the west (Cutlip, 1990; Cash, 2002), possibly indicating that more experienced institutions have developed more relational embeddedness interactions. This finding of geographic differences partially confirms the assumption in Hypothesis $1 \mathrm{~b}$ that institutional characteristics would differ based on quadrant. 
Integration Strategies Utilized by Quadrant Membership Hypothesis 2 addressed whether integration strategies utilized by institutions differed by DOIM quadrant membership. Factor analysis identified seven specific donor integration strategies: structure, strategic vision, planning, donor commitment, inner circle connectivity, internal networking, and external networking (see Table 1), each aligning with previous research (Chung-Hoon et al., 2005). The four DOIM quadrants were analyzed using $t$-tests for differences between these seven donor integration strategies.

Comparing the functional and the latent/potential integration quadrants, only one significant difference in donor integration strategy was identified. Institutions in the latent/potential quadrant utilized inner circle connectivity strategies significantly more $(p<0.05)$ than did institutions in the functional quadrant. Institutions in the latent/potential quadrant had 32 percent of their inner circle donors connected to the top campus official, in comparison to only nine percent connectivity to top officials of inner circle donors for institutions in the functional quadrant.

When institutions in the isolated and full integration quadrants were compared, significant differences were identified in their use of three specific donor integration strategies: strategic vision, commitment, and inner circle connectivity. First, institutions in the full integration quadrant had significantly more $(p<0.001)$ confidence in their ability to communicate and utilize strategic vision with their top donors for a competitive advantage in fund raising efforts than did institutions in the isolated quadrant. Secondly, institutions in the full integration quadrant were significantly more likely $(p<0.05)$ than isolated integration institutions to use a commitment strategy, defined as top 10 donors committing to make continued annual gifts in addition to major gift commitments. Institutions in the isolated quadrant averaged only 50 percent of their top donors giving annual gifts in addition to major gifts, whereas full integration institutions averaged 70 percent of their top donors committed to giving annual gifts. Lastly, institutions in the full integration quadrant had 50 percent of their top donors engaged in significant inner circle relationships with the top campus officials, compared to only 24 percent for institutions in the isolated integration quadrant $(p<0.05)$. Hypothesis 2 is thus confirmed as specific strategies were associated with specific quadrant membership.

\section{Correlation of Study Constructs}

Hypotheses $3 \mathbf{a}$ and $\mathbf{3 b}$ addressed the association of donor integration strategies with the institutional outcomes of both EDR and FRO. Findings provided insights for both within and between construct categories. Within the construct of donor integration strategies, only planning and strategic vision were positively correlated $(p<0.01)$, suggesting that the seven strategies were generally distinct and do represent a useful range. Within the construct of EDR, only donor initiates contact and donor asks for and takes suggestions were positively correlated $(p<0.01)$, again supporting that 
variables in this construct generally represented separate measures.

Within the construct of FRO, each of the variables were significantly and positively correlated with the others, suggesting that a single variable may be efficient. This finding supported the factor analysis identified earlier. The multiple perspectives offered by the data provided by the variables individually were of more practical use in evaluating fund-raising success. Therefore, further analysis continued to examine each variable independently. Between the constructs, three significant correlations out of 12 (25 percent) were found between EDR variables and FRO. These findings indicated that a primary charitable focus was positively correlated with total fund-raising dollars and unrestricted dollars $(p<0.05)$. The number of ultimate donors was also related to unrestricted dollars $(p<0.01)$.

Regarding Hypothesis 3a, findings indicated that four of the seven donor integration strategies, planning, commitment, inner circle connectivity and personal friend, were significantly correlated with EDR. First, planning (which was positively correlated with the strategic vision) was positively correlated with ultimate donors $(p<0.01)$ and donor-initiated contact $(p<0.05)$. Secondly, commitment was positively correlated with donorinitiated contacts $(p<0.01)$. Thirdly, inner circle connectivity was positively correlated with number of ultimate donors $(p<0.05)$ and donor-initiated contacts $(p<0.05)$. Lastly, personal friend was positively correlated with both donor-initiated contacts $(p<0.01)$ and donor asks for and takes suggestions $(p<0.01)$.
Regarding Hypothesis 3b, findings indicate that two donor integration strategies were significantly correlated with FRO: planning and structural embeddedness. First, planning (which was positively correlated with strategic vision) was positively correlated with unrestricted donations $(p<0.05)$. Secondly, structural embeddedness was negatively correlated with alumni donors $(p<0.05)$. Given that four of the seven donor integration strategies (42 percent) were related to EDR, Hypotheses $3 \mathbf{a}$ is considered to be moderately confirmed. Given that only two of the seven donor integration strategies (29 percent), however, were related to FRO, Hypothesis $3 \mathrm{~b}$ is not fully supported.

\section{Fund-raising Outcomes}

Hypotheses 4a addressed whether EDR differed by DOIM quadrant membership. Statistically significant differences between quadrants were manifest in EDR. First, latent/potential integration institutions had five times more ultimate donors $(x=27.4)$ than functional integration institutions $(x=5.0 ; p<0.05)$. Ultimate donors are those who have given the largest gift they are capable of making in a lifetime (Dunlop, 1987). Ultimate gift giving may not necessarily mean large dollar amounts, especially if a donor has limited gift capacity. Ultimate gifts to an institution are, however, invaluable, especially as ultimate donors become volunteers in asking others to consider making similar types of gifts. Secondly, latent/potential integration institutions were twice as likely to have donor-initiated contact compared to functional integration institutions. No statistically significant 
differences were found between isolated integration and full integration institutions in terms of EDR. These findings provided moderate support for Hypothesis 4a that EDR would differ by DOIM quadrant, as significant differences were evident between only two of the four quadrant groups.

Hypothesis $4 \mathrm{~b}$ addressed whether FRO would differ by DOIM quadrant. Contrary to expectations, no statistically significant differences were found between quadrant groups on FRO. Therefore, Hypothesis $4 \mathrm{~b}$ was not directly supported. While this finding, however, indicated lack of direct effects of quadrant membership on FRO, the correlation analysis (for Hypothesis $\mathbf{3 a}$ and $\mathbf{3 b}$ ) provides an explanation of possible indirect effects of quadrant membership based on integration strategies and the development of EDR, which suggests that both full and latent/potential quadrants may be indirectly related to unrestricted donations. While quadrant differences were not statistically significant, the differences in outcomes indicate differences of practical value that will be presented and discussed in the next section.

\section{Discussion}

Based on the findings, the DOIM (Chung-Hoon et al., 2005) provides value in enabling the classification of institutions and fund-raising efforts to facilitate the building of committed EDR that benefit both the donor and the institution. While the DOIM was examined in earlier qualitative research (Chung-Hoon et al., 2005), in a case study of three public higher education institutions, this quantitative study sought to further examine this model from a quantitative perspective. Thus, the DOIM has now been examined and supported in the context of public higher education from the perspective of two different research paradigms (Gay and Airasian, 2000).

The DOIM presents a new typology for classifying donor integration within an institution. This is important because the first step in making deliberate and strategic changes for attracting and retaining donors is for an organization to understand its current position (Mintzberg, 1981; Clawson, 1999; Daft, 2000). That the institutions were somewhat evenly distributed into each of the four quadrants indicates that not all institutions approach fund raising the same way.

The DOIM provides a useful tool for leaders in public higher education, particularly those responsible for and/or directly involved in fund raising, to find and define their institution's place in the philanthropy "market." The model is a useful framework to identify an organization's fund-raising competitive advantage and to articulate specific donor integration strategies that set them apart from their competition.

DOIM placement clarified the focus of institutional interactions with donors. For example, an institution may choose to focus only on simple structural interactions (low formal structural interaction) or to focus their efforts on more complex organizational-level interactions (high formal structural interaction). Further, an institution may choose to focus on simpler individual donor relationships or to focus on more complex, robust, and embedded donor relationships. While these choices may seem 
independent, the combination stands to have critical implications for fundraising success in public higher education institutions. A focus on more complex donor interactions, particularly in terms of relational embeddedness (latent/potential quadrant), was related to greater EDR. Specifically, these institutions were most likely to engage in the donor integration strategy of inner circle connectivity, which was significantly related to EDR in terms of ultimate donors and donor-initiated contacts. A donor that is highly engaged with an institution will be more proactive in seeking to help solve institutional challenges, and will be more likely to develop into an ultimate gift giver. Given that ultimate donors is also correlated with unrestricted donations, the conclusion can be drawn that the latent/potential quadrant is well positioned to achieve EDR and to indirectly achieve successful FRO.

The combination of both higher relational embeddedness and formal structural interactions (full integration quadrant), however, adds greater depth and quality to both dimensions of interaction. The strategy of inner circle connectivity also added the two donor integration strategies of planning and commitment, which were related to EDR (ultimate donors and donorinitiated contacts) but also directly to the fund-raising outcome of unrestricted donations. Thus the conclusion can be suggested that institutions in the full integration quadrant have more direct access to unrestricted funds due to their additional focus on formal structural interactions with donors.

Four additional findings related to the full integration quadrant clearly

Table 2: DOIM group membership comparison of means on selected survey variables

\begin{tabular}{|c|c|c|c|c|}
\hline Variable & $\begin{array}{l}\text { Group } 1 \\
\text { Isolated }\end{array}$ & $\begin{array}{l}\text { Group } 2 \\
\text { Functional }\end{array}$ & $\begin{array}{l}\text { Group } 3 \\
\text { Relational }\end{array}$ & $\begin{array}{l}\text { Group } 4 \\
\text { Integrated }\end{array}$ \\
\hline ORGAGE-Age of institution in years & 124.00 & 93.11 & 120.13 & 123.54 \\
\hline $\begin{array}{l}\text { STRATEGY-Ongoing and well communicated } \\
\text { (1-5 Scale) }\end{array}$ & 3.00 & 3.21 & 3.40 & 4.29 \\
\hline NUMBFR-Number of fund raisers at institution & 49.51 & 19.83 & 36.38 & 70.72 \\
\hline FREXP—Fund raising experience* (1-8 Scale) & 4.87 & 6.11 & 4.96 & 5.72 \\
\hline $\begin{array}{l}\text { PLANREL_planned initiatives out of } 10 \\
\text { for fund raising relations }\end{array}$ & 6.96 & 6.25 & 7.21 & 8.11 \\
\hline $\begin{array}{l}\text { NUMQUAL-Maximum \# of donors } \\
\text { and maintain quality relationship }\end{array}$ & 98.25 & 59.29 & 75.68 & 73.78 \\
\hline ALUMNI-Top 10 donors that are alumni & 7.85 & 7.00 & 8.11 & 8.02 \\
\hline $\begin{array}{l}\text { Unrestricted-VSE report average amount of } \\
\text { unrestricted gifts*** }\end{array}$ & 29,590 & 12,213 & 33,173 & 43,590 \\
\hline $\begin{array}{l}\text { Alumni donors-\# of Alumni donors reported } \\
\text { on VSE }\end{array}$ & 16,958 & 9,346 & 17,225 & 20,403 \\
\hline $\begin{array}{l}\text { Endowment level-Average endowment level } \\
\text { for institution } * *\end{array}$ & $\$ 224,706$ & $\$ 141,856$ & $\$ 368,968$ & $\$ 402,078$ \\
\hline
\end{tabular}

"Categorical $-1=0-1$ years; $2=1-3$ years; $3=4-6$ years; $4=7-9$ years; $5=10-12$ years; $6=13-15$ years; $7=16-19$ years; $8=$ over 20 years. $* *(000)$. 
showed the influence of inner circle integration strategies on fund-raising success (see Table 2). While these influences were not shown to be statistically significant, the difference in means is significant at a practical level, given that institutional leaders are continuously seeking for ways to improve their bottom-line outcomes (Payton, 1991; Duderstadt, 1997; Young, 1997; Kelly, 1998; Cash, 2002). These influences also provide additional support for Hypothesis $3 b$. First, full integration institutions, identified as having a high degree of both relational embeddedness interaction and formal structural interaction, had the highest average numbers of inner circle relationships (integration strategy), particularly with the top campus officials than other quadrants. Secondly, institutions in the full integration quadrant also had the highest indicators of EDR, specifically in terms of the number of ultimate gift donors and donor-initiated contact. Thirdly, these institutions also had the highest FRO, specifically in terms of endowment levels, number of alumni donors, and amounts of unrestricted gifts. Fourthly, the full integration institutions also had the highest average number of fundraisers at their institutions and were the most confident in their ability to communicate their fund-raising strategy for a competitive advantage. Thus full integration institutions clearly participated in integration strategies that promote enduring donor relationships and would enable them to outperform institutional competitors.

Lessons may also be, however, learned from the isolated, functional, and latent/potential integration institutions in terms of enduring donor relationship development. The second most productive institutions, in terms of FRO, were those in the latent/ potential integration quadrant. These institutions were involved with integration strategies that most closely aligned with traditional fund-raising practices that focus more on relationships and donors than on the organization (Prince and File, 1994; Drummond, 1997; A.S.C. Grant, 2001; Bloland, 2002). While latent/potential institutions did not have the greatest number of fundraisers, they felt more confident than functional and full integration institutions in their ability to maintain larger numbers of quality relationships, although not statistically more so. These institutions also had the highest mean number of top ten donors who were alumni, which again reinforces the donor focus on maintaining relational ties with the institution once these relationships are established.

Functional integration institutions were, on average, the youngest in terms of institutional age. They had the lowest average number of fund raisers, yet their fund raisers were the most experienced. This finding may be explained by an efficiency focus: an institution limited in the number of fundraisers would likely seek fundraisers with the greatest experience. Functional integration institutions, however, were also least likely to plan their initiatives, perhaps because of limitations on time and staff. Functional integration institutions had the lowest average number of alumni in their inner circle, the lowest average total number of alumni donors, and the lowest endowment average totals. These findings seem to 
bear out a time/scale diseconomy, suggesting that less institutional experience means (1) less time to connect with donors, (2) fewer potential alumni to draw on as a likely donor pool, and (3) less time for an endowment to grow (Bain, 1956). These outcomes parallel expectations for institutions that focus on structure and formality before relationships (Duderstadt, 1997; Kelly, 1998). Time may contribute to fund-raising success, but the DOIM shows that utilizing full integration strategies, by adding relational embeddedness interactions, may be able to accelerate institutional success.

Isolated integration institutions did not stand out in any specific way in terms of integration strategies, EDR or FRO. This finding confirms the consistency of the DOIM because institutions in this quadrant were expected to have the fewest integration strategies due to their lower relational embeddedness interaction and lower formal structural interaction, and the lowest institutional outcomes.

Given that the study focused on the institution's top ten donors, the findings best explain the relationship between integration strategies and institutional outcomes among this group of donors. Findings indicate that full integration institutions were more inclined than institutions in the isolated integration quadrant to share their strategic vision, to emphasize commitment to making an annual gift, and to focus on inner circle connectivity. As a result, they would be more likely to exhibit both higher levels of EDR (ultimate donors and donor-initiated contacts) and FRO (unrestricted donations). The functional and latent/potential quadrant institutions also significantly differed $(p<0.001)$ with latent/potential quadrant exhibiting greater use of inner circle connectivity strategies.

These findings generate a proposed theoretical model that illustrates the potential relationships between DOIM

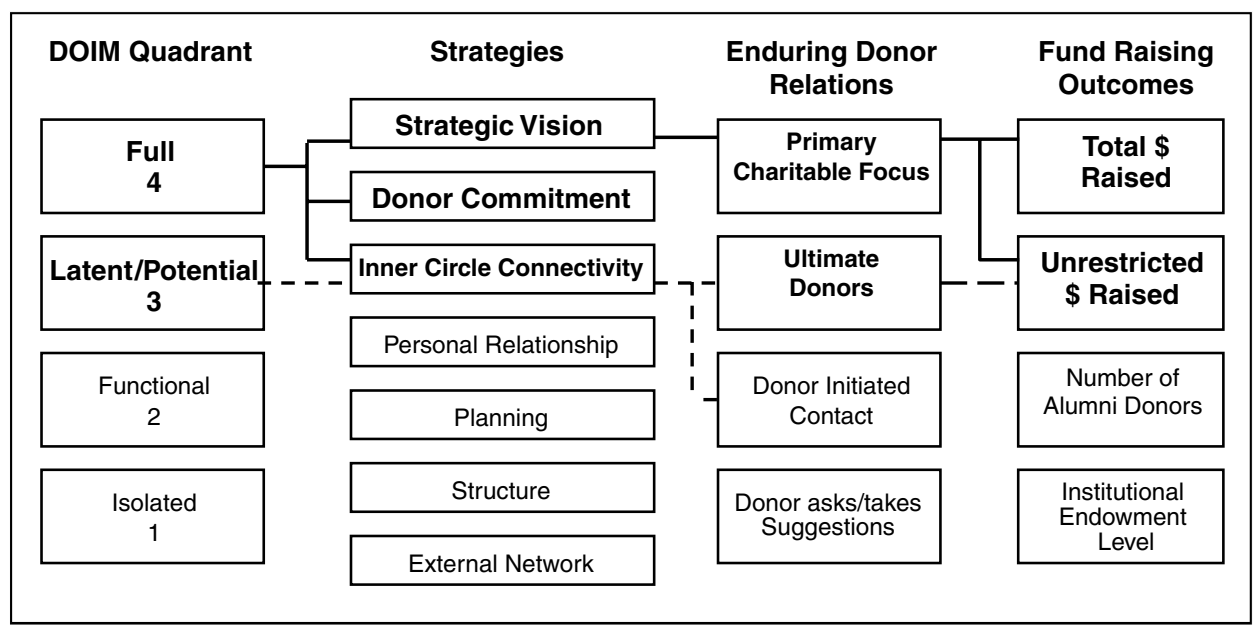

_ Full Integration Path - _ - _ - Relational Embeddedness Path

Figure 3: Paths of most significant association for factors and constructs in the DOIM. 
quadrant membership and institutional outcomes (see Figure 3). The isolated and functional integration quadrants demonstrate no connection with donor integration strategies and therefore no connection with institutional outcomes. The latent/potential integration quadrant indicates a clear path through inner circle connectivity to ultimate donors to unrestricted donations. The full integration quadrant demonstrates this same path. Thus, the donor integration strategy of inner circle connectivity overlaps in both paths providing direct link to ultimate donors and through them to unrestricted funds. Both paths have relational embeddedness interactions in common.

In addition, however, the full integration quadrant also demonstrates a more direct path to unrestricted funds through planning (correlated with strategic vision). This direct path results, however, not from the simple addition of formal structural interactions (since functional quadrant did not show this path) but rather from the synergistic combination of both relational and structural interactions.

Future research should consider organizational maturity or evolution of fund-raising operations in public higher education organizations rather than merely a snapshot in time. Future inquiry should also question whether there is a defined course or time frame that institutions must pass through before they are successful. Can younger institutions accelerate their fund-raising growth and capacity by simply adopting the practices of more mature schools? Given that purposeful sampling limits generalizing the findings to only the institutions within the study population, the DOIM should also be tested across a broader spectrum of higher education institutions, both public and private, to further confirm its validity. Ideally, a more rigorous statistical analysis, such as LISREL, may also provide more insight into the most fruitful paths from donor interactions to institutional outcomes.

\section{Conclusion}

Organizations seeking to improve fund-raising success may increase their ability to achieve this goal by focusing on more complex relational and structural donor interactions. Full donor/organization integration, based on a high-level balance of both relational and structural interactions, demonstrated greater use of internal policy, strategies and management practices that can lead to fund-raising success. Finding this balance may be enhanced through institutional fundraising policy and practice analysis. Full donor/organization integration resulted in more ultimate donors with stronger ties to the institution. These ultimate donors also identified the higher education organization as their primary charitable focus. Relationships with fully integrated donors provided the benefit of greater unrestricted gift giving, which increased the higher education institution's autonomy in the use of the funds they raise thus providing a significant boon as leaders manage institutional financial challenges. Clearly, the theory and the integration strategies identified for building enduring donor relationships warrant additional consideration as they add to the emerging knowledge 
base of fund-raising theory as well as to the practices that seek to generate enduring relationships with top donors to provide sustainable and reliable financial support for higher education.

\section{References}

Altbach, P.G. (2004), "The costs and benefits of world-class universities," Academe, 90, 1, p. 20 .

Bain, J.S. (1956), "Importance of the condition of entry," in Barriers to New Competition, Harvard University Press, Cambridge, pp. 1-41.

Barney, J. (1991), "Firm resources and sustained competitive advantage," Journal of Management, 17, 1, pp. 99-120.

Bloland, H.G. (2002), "No longer emerging, fund raising is a profession," The Case International Journal of Educational Advancement, 3, 1, pp. 7-19.

Carnegie (2000), Carnegie Classification: The Carnegie Classification of Institutions of Higher Education, accessed 11/14/02, www. carnegiefoundation.org/classification/CIHE2000/ background.htm: Carnegie Foundation.

Cash, J. (2002), "Private fund raising for public higher education. The first fifteen years: A progress report" (Consultants Study): Marts \& Lundy.

Chung-hoon,, T.L. (2005), "Beyond give and take: A donor/organization integration model for enduring relations in public higher education fund raising," Unpublished dissertation, Department of Educational Leadership and Foundations, Brigham Young University, Provo, UT, USA.

Chung-Hoon, T.L., Hite, J. and Hite, S. (2005), "Searching for enduring donor relations: Evidence for strategies and factors in a donor/organization integration model for fund raising," International Journal of Educational Advancement, 6, pp. 34-53.

Clawson, J.G. (1999), "Chapter 1: The changing context of leadership," in Level Three Leadership: Getting Below the Surface, PrenticeHall, Inc., Upper Saddle River, NJ, pp. 1-15.

Council for Advancement of Education (CAE) (2002), Annual Report, RAND, New York.

Council for Advancement of Education (CAE) (2003, March 13, 2003), "Gifts to higher education drop for the first time in 15 years; giving by alumni shows biggest drop".

Cutlip, S.M. (1990), Fund Raising in the United States: Its Role in America's Philanthropy,
Transaction Publishers, New Brunswick, NJ (original work published 1965).

Daft, R.L. (2000), Leadership: Theory and Practice, 1st edn., Harcourt Brace College Publishers, Forth Worth, pp. 495.

Dierickx, I. and Cool, K. (1989), “Asset stock accumulation and sustainability of competitive advantage," Management Science, 35, 12, pp. 1504-1511.

Drummond, M.B. (1997), "The power of money: Colleges and universities bank on the boundaryspanning roles of development officers," Unpublished dissertation-EdD, Oklahoma State University.

Duderstadt, J.J. (1997), "Successful fund raising at a large public research university," in F.H.T. Rhodes (ed.), Successful Fund Raising for Higher Education, Council for the Advancement of Education (CAE), Oryx Press, Phoenix, AZ.

Dunlop, D.R. (1987), “The ultimate gift," CASE Currents, May, 8-13.

Durham, M.L. and Smith, A.B. (2001), "Assessing the fund-raising process at a public research II university and refining the process framework," The Case International Journal of Educational Advancement, 2, 1, pp. 67-78.

Dyer, J.H. and Singh, H. (1998), “The relational view: Cooperative strategy and sources of interorganizational competitive advantage," Academy of Management Review, 23, 4, pp. 660-679.

Gay, L.R. and Airasian, P. (2000), "Chapter 1: Introduction to educational research," in Educational Research: Competencies for Analysis and Application, 6th edn., Prentice-Hall, Upper Saddle River, NJ, pp. 3-36.

Gonzalez-Campoy, R. (1996), “Answering the call for help," NSFRE Advancing Philanthropy, (Spring), 4 pp. 36-40.

Grant, A.S.C. (2001), "Major gift donor stewardship in higher education", Ph.D. dissertation, College of Education, Washington State University, Pullman, Washington, 178pp., available from http://proquest.uml.com/pqdweb? $\mathrm{did}=725926061 \&$ sid $=1 \& \mathrm{Fmt}=2 \&$ clientid $=9338$ \&RQT $=309 \&$ VName=PQD.

Grant, R.M. (2001), Contemporary Strategy Analysis, Blackwell Publishers Ltd, Oxford, UK.

Hall, P.D. (1992), Inventing the Nonprofit Sector and Other Essays on Philanthropy, Voluntarism, and Nonprofit Organizations, Johns Hopkins University Press, Baltimore, MD.

Havens, J.J. and Schervish, P.G. (2001), "Wealth and commonwealth: New findings on wherewithal and philanthropy," Nonprofit and Voluntary Sector Quarterly, 30, 1, pp. $5-25$. 
Hite, J.M. (2003), "Patterns of multidimensionality among embedded network ties: A typology of relational embeddedness in emerging entrepreneurial firms," Strategic Organization, 1, 1, pp. 9-49.

Jackson, K.L. and Glass, J.C. Jr. (2000), “Emerging trends and critical issues affecting private fundraising among community colleges," Community College Journal of Research and Practice, 24, 9, pp. 739-754.

Kelly, K.S. (1995), “The fund-raising behavior of US charitable organizations," Journal of Public Relations Research, 7, 2, pp. 111-137.

Kelly, K.S. (1998), Effective Fund-Raising Management, Lea's Communication Series, 1st edn., Lawrence Erlbaum Associates, Mahwah, NJ.

Loessin, B.A. and Duronio, M.A. (1993), "Characteristics of successful fund-raising programs”, in M.J. Worth (ed.), Educational Fund Raising: Principles and Practice, American Council on Education, Oryx Press, Phoenix, AZ, pp. 39-50.

Lord, J.G. (1983), The Raising of Money: ThirtyFive Essentials Every Trustee Should Know, Third Sector Press, Cleveland, OH.

Mintzberg, H.H. (1981), “Organization design: Fashion or fit? Harvard Business Review, January/February, 59, 1, pp. 93-109.

Mora, J.-G. and Nugent, M. (1998), "Seeking new resources for European universities: The example of fund-raising in the US," European Journal of Education, 33, 1, pp. 113-140.

Nicklin, J.L. (1995 May 19, 1995), "Seated on the bottom line: Trustees are being asked to show commitment with donations: Colleges are now judging prospective trustees as donors and fund raisers," Chronicle of Higher Education, 41, pp. A37-A38.

Panas, J. (1984), Megagifts: Who Gives Them Who Gets Them, Pluribus Press, Chicago.

Payton, R.L. (1991), "Foreward", in H.A.R.A. Associates (ed.), Achieving Excellence in Fund Raising: A Comprehensive Guide to Principles, Strategies, and Methods, Jossey-Bass,

San Francisco, CA, pp. xiii-xv.

Prince, R.A. and File, K.M. (1994), The Seven Faces of Philanthropy, Jossey-Bass Publishers, San Francisco, CA.
Schaefer, D.R. and Dillman, D.A. (1998), "Development of a standard e-mail methodology," Public Opinion Quarterly, 62, 3, pp. 378-398.

Schervish, P.G. (1997), "Major donors, major motives: The people and purposes behind major gifts", in D.F. Burlingame and J.M. Hodge (eds.), New Directions for Philanthropic Fundraising: Developing Major Gifts, Jossey-Bass Publishers, pp. 85-112.

Schervish, P.G. (2001), "The spiritual horizons of philanthropy: New directions for money and motives", in E.R. Tempel and D.F. Burlingame (eds.), Understanding the Needs of Donors: The Supply Side of Charitable Giving, Vol. 29, Jossey-Bass Publishers, San Francisco, California, pp. 101.

Surveymonkeycom. (2004, November 16, 2004), "Survey monkey", Retrieved October 1, 2004, 2004, from www.surveymonkey.com.

Taylor, M.A. and Shaw, S.C. (1997), "Women as philanthropists: Leading transformation in major gift fundraising”, in D.F. Burlingame and J. M. Hodge (eds.), Developing Major Gifts, Vol. 16 Jossey-Bass Publishers, San Francisco, California, pp. 116.

Tempel, E.R. (1991), “Assessing Organizational Strengths and Vulnerabilities", in H.A.R.A. Associates (ed.), Achieving Excellence in Fund Raising: A Comprehensive Guide to Principles, Strategies, and Methods, Jossey-Bass, San Francisco, CA, pp. 19-27.

Thompson, J.D. (1967), Organizations in Action: Social Science Bases on Organizational Theory, McGraw Hill, New York.

Uzzi, B. (1996), "The sources and consequences of embeddedness for the economic performance of organizations: The network effect," American Sociological Review, 61, August, pp.674-698.

Whipple, J.M. and Frankel, R. (2000), "Strategic alliance success factors," Journal of Supply Chain Management, 36, Summer, pp. 21-28.

Young, C.E. (1997), "Successful fund raising at a large public research university with a foundation", in F.H.T. Rhodes (ed.), Successful Fund Raising for Higher Education, Oryx Press, Phoenix, AZ, pp. 188. 